\title{
Isolation and Identification of Black Yeasts by Enrichment on Atmospheres of Monoaromatic Hydrocarbons
}

\author{
Jingjun Zhao • Jingsi Zeng • G. Sybren de Hoog • \\ Derlene Attili-Angelis • Francesc X. Prenafeta-Boldú
}

Received: 31 December 2009 /Accepted: 21 February 2010/Published online: 24 March 2010

(C) The Author(s) 2010. This article is published with open access at Springerlink.com

\begin{abstract}
Black yeast members of the Herpotrichiellaceae present a complex ecological behavior: They are often isolated from rather extreme environments polluted with aromatic hydrocarbons, while they are also regularly involved in human opportunistic infections. A selective technique to promote the in vitro growth of herpotrichiellaceous fungi was applied to investigate their ecophysiology. Samples from natural ecological niches and man-made environments that might contain black yeasts were enriched on an inert solid support at low humidity and under a controlled atmosphere rich in volatile aromatic hydrocarbons. Benzene, toluene, and xylene were provided separately as the sole carbon and energy source via the gas phase. The assayed isolation protocol was highly specific toward mesophilic Exophiala species (70 strains of this genus out of 71 isolates). Those
\end{abstract}

\section{J. Zhao}

Department of Dermatology,

Fujian Medical University Affiliated Union Hospital,

Fuzhou, People's Republic of China

\section{J. Zeng}

Department of Dermatology and Venereology,

Union Hospital, Tongji Medical College,

Huazhong Science and Technology University,

Jiefang Dadao,

Wuhan, Hubei, People's Republic of China

G. S. de Hoog

CBS-KNAW Fungal Biodiversity Centre,

Utrecht, The Netherlands

G. S. de Hoog

Institute of Biodiversity and Ecosystem Dynamics,

University of Amsterdam,

Amsterdam, The Netherlands were obtained predominantly from creosote-treated railway ties (53 strains), but isolates were also found on wild berries (11 strains) and in guano-rich soil samples (six strains). Most of the isolates were obtained on toluene (43 strains), but enrichments on xylene and benzene also yielded herpotrichiellaceous fungi (17 and 10 isolates, respectively). Based upon morphological characterizations and DNA sequences of the full internal transcriber spacers (ITS) and the $8.5 \mathrm{~S}$ rRNA genes, the majority of the obtained isolates were affiliated to the recently described species Exophiala xenobiotica (32 strains) and Exophiala bergeri (nine strains). Members of two other phylogenetic groups (24 and two strains, respectively) somewhat related to E. bergeri were also found, and a last group (three strains) corresponded to an undescribed Exophiala species.

G. S. de Hoog

Research Center for Medical Mycology,

Peking University Health Science Center,

Beijing, China

D. Attili-Angelis

UNESP Department of Biochemistry and Microbiology,

Institute of Biosciences,

Rio Claro, SP, Brazil

F. X. Prenafeta-Boldú $(\bowtie)$

GIRO Technological Centre,

Pompeu Fabra 1, 08100 Mollet del Vallès,

Barcelona, Catalonia, Spain

e-mail: francesc.prenafeta@giroct.irta.cat

F. X. Prenafeta-Boldú

IRTA,

Barcelona, Spain 


\section{Introduction}

Black yeasts from the family Herpotrichiellaceae (order Chaetothyriales) are fungi with a remarkable dual ecology. On the one hand, they have a unique ability to adapt to extreme environments (exposure to toxic chemicals, high temperature, scarcity of nutrients, acidic, and/or dry conditions), while on the other hand, they exhibit a significant human pathogenic potential. Unlike common opportunistic fungi, herpotrichiellaceous black yeasts frequently cause infections in individuals without known underlying disease [13] and only occasionally in immunocompromised patients. Also, more often than any other fungal group, these organisms have been reported from environments that are rich in aromatic compounds. The first evidence on such phenomenon arose from the frequent isolation of black yeasts from wood treated with creosote [28], while their occurrence on untreated wood was comparatively low, indicating that accumulation of aromatic compounds might promote the growth of these fungi.

The concurrence of these two ecological traits in a single species has been observed for Exophiala dermatitidis, isolated abundantly not only on tropical creosoted railway ties but also from clinical cases of severe mycoses [26, 27]. It has been hypothesized that wild berries constitute a natural niche of $E$. dermatitidis, which might then be ingested by birds and humans and sporadically resulting in mycoses. Deposition of feces on creosoted railway ties subsequently leads to the massive enrichment of this fungus. The related species Exophiala bergeri, Exophiala heteromorpha, Exophiala oligosperma, and Exophiala xenobiotica have also been reported as opportunistic fungi causing infections that are generally less serious and from creosoted wood [5-7, 11, 27]. However, the connection between route of infection and natural occurrence is less evident with these species.

The tendency of herpotrichiellaceous fungi toward aromatic metabolism has been confirmed by their recurrent isolation from biofilters treating vapors of volatile aromatic hydrocarbons [21]. Besides hydrocarbon exposure, environmental conditions in biofilters are characterized by a relative low water activity and acidification of the filter bed, which might lead to biomass inhibition problems. In this respect, fungal colonization in air biofilters has generally been related to an improved bioreactor performance [16]. Detailed metabolic studies on fungi from gas biofilters have demonstrated their capacity to assimilate alkylbenzene hydrocarbons as the sole source of carbon and energy $[3,20,29]$, which appears to be quite an uncommon metabolic feature in the eukaryotes. Molecular phylogenetic characterization of these "biofilter fungi" has shown a predominant affiliation to the genera Exophiala and Cladophialophora (fam. Herpotrichiellaceae), particularly to the species Exophiala lecanii-corni, E. oligosperma [21], and the recently described E. xenobiotica, Cladophialophora saturnica, and Cladophialophora inmunda $[1,6]$.

Despite the medical and environmental relevance of herpotrichiellaceous black yeasts, little is understood on their biodiversity and natural occurrence. In order to address questions on niche shifts and environmental prevalence in relation to virulence factors and routes of transmission, the application of selective isolation techniques is fundamental. The aim of the present work is to apply a specific isolation method based on the enrichment of black yeasts by simulating in batch solid state-like cultures the environmental conditions that are found in gas biofilters for the treatment of volatile aromatic hydrocarbons. Different environmental samples related to the life cycle of $E$. dermatitidis were used as inocula.

\section{Materials and Methods}

\section{Sampling}

The list of sampled sites that were used as source of inoculum for the subsequent enrichment cultures is presented in Table 1. These samples were collected around Utrecht (The Netherlands) and concerned wild berries from different plants, guano-rich soil, as well as samples from creosotetreated oak railway ties, which might contain both fecal pollution and contamination with aromatic hydrocarbons. Environmental samples were collected with sterile lab tools, placed in plastic bags and plates, then stored at $4^{\circ} \mathrm{C}$, and processed in the laboratory within 7 to 14 days. The same locations had previously been sampled for black yeasts, but without enrichment on volatile aromatic hydrocarbons [18].

Isolation

The solid state-like batch culture technique on a hydrocarbon atmosphere was employed to select for fungi that are able to grow on volatile aromatic hydrocarbons as the sole carbon and energy source [20]. Serum flasks of $100 \mathrm{~mL}$ were filled with approximately $25 \mathrm{~mL}$ of perlite granules, saturated with mineral medium [19]. Each environmental sample (1-3 g) was washed with phosphate-buffered saline, and the suspension $(40 \mathrm{~mL})$ was used to inoculate four different batches $(10 \mathrm{~mL}$ each batch). As a control, these suspensions were also plated on Sabouraud's glucose agar (SGA) amended with antibiotics in order to prevent bacterial growth. The inoculated flasks were then closed with a cotton-wool plug covered with aluminum foil and placed inside four desiccators where they were exposed, respectively, to a gaseous phase of benzene, toluene, xylene, or naphthalene. This gas phase was generated by 
Table 1 Samples and sampling sites in the Utrecht area (The Netherlands) used as source of inocula for the enrichment with volatile aromatic hydrocarbons

\begin{tabular}{|c|c|c|c|}
\hline Code & Sample & Sampling location & Geographic coordinates (WGS84) \\
\hline A1 & Oak railway tie, outside rails & Near station, Hollandsche Rading & $52^{\circ} 10^{\prime} 41.95^{\prime \prime} \mathrm{N}, 5^{\circ} 10^{\prime} 45.96^{\prime \prime} \mathrm{E}$ \\
\hline $\mathrm{A} 2$ & Oak railway tie, between rails & Near station, Hollandsche Rading & $52^{\circ} 10^{\prime} 41.95^{\prime \prime} \mathrm{N}, 5^{\circ} 10^{\prime} 45.96^{\prime \prime} \mathrm{E}$ \\
\hline A3 & Oak railway tie, outside rails & Forest area, Hilversum & $52^{\circ} 12^{\prime} 20.68^{\prime \prime} \mathrm{N}, 5^{\circ} 11^{\prime} 9.66^{\prime \prime} \mathrm{E}$ \\
\hline A4 & Oak railway tie, between rails & Forest area, Hilversum & $52^{\circ} 12^{\prime} 20.68^{\prime \prime} \mathrm{N}, 5^{\circ} 11^{\prime} 9.66^{\prime \prime} \mathrm{E}$ \\
\hline A5 & Concrete railway tie, between rails & Forest area, Hilversum & $52^{\circ} 12^{\prime} 20.68^{\prime \prime} \mathrm{N}, 5^{\circ} 11^{\prime} 9.66^{\prime \prime} \mathrm{E}$ \\
\hline $\mathrm{C} 1$ & Berry, Sorbus aucuparia & Roadside, De Bilt & $52^{\circ} 7^{\prime} 17.18^{\prime \prime} \mathrm{N}, 5^{\circ} 9^{\prime} 48.13^{\prime \prime} \mathrm{E}$ \\
\hline $\mathrm{C} 2$ & Berry, Sorbus aucuparia & Light forest, Voordaansepad, Groenekan & $52^{\circ} 7^{\prime} 49.19^{\prime \prime} \mathrm{N}, 5^{\circ} 9^{\prime} 31.42^{\prime \prime} \mathrm{E}$ \\
\hline $\mathrm{C} 3$ & Berry, Sorbus aucuparia & Light hedge, Oostveensepad, Maartensdijk & $52^{\circ} 8^{\prime} 33.70^{\prime \prime} \mathrm{N}, 5^{\circ} 9^{\prime} 51.98^{\prime \prime} \mathrm{E}$ \\
\hline $\mathrm{C} 4$ & Berry, Sorbus aucuparia & Lapersveld Park, Hilversum & $52^{\circ} 12^{\prime} 54.74^{\prime \prime} \mathrm{N}, 5^{\circ} 11^{\prime} 10.25^{\prime \prime} \mathrm{E}$ \\
\hline $\mathrm{C} 5$ & Berry, Viburnum opulus & Light hedge, Oostveensepad, Maartensdijk & $52^{\circ} 8^{\prime} 33.70^{\prime \prime} \mathrm{N}, 5^{\circ} 9^{\prime} 51.98^{\prime \prime} \mathrm{E}$ \\
\hline C6 & Berry, Crataegus monogyna & Hedge, Vuursche pad, Hollandsche Rading & $52^{\circ} 10^{\prime} 10.52^{\prime \prime} \mathrm{N}, 5^{\circ} 10^{\prime} 51.99^{\prime \prime} \mathrm{E}$ \\
\hline D1 & Guano-rich soil of jackdaw and starling & Lapersveld Park, Hilversum, roosting under Thuja & $52^{\circ} 12^{\prime} 54.74^{\prime \prime} \mathrm{N}, 5^{\circ} 11^{\prime} 10.25^{\prime \prime} \mathrm{E}$ \\
\hline D2 & Guano-rich soil covered with Hedera sp. & Lapersveld Park, Hilversum, roosting under Thuja & $52^{\circ} 12^{\prime} 54.74^{\prime \prime} \mathrm{N}, 5^{\circ} 11^{\prime} 10.25^{\prime \prime} \mathrm{E}$ \\
\hline D3 & Guano-tic soil of jackdaw and starling & Lapersveld Park, Hilversum, roosting under Thuja & $52^{\circ} 12^{\prime} 54.74^{\prime \prime} \mathrm{N}, 5^{\circ} 11^{\prime} 10.25^{\prime \prime} \mathrm{E}$ \\
\hline D4 & Fresh goose feces & Lapersveld Park, Hilversum & $52^{\circ} 12^{\prime} 54.74^{\prime \prime} \mathrm{N}, 5^{\circ} 11^{\prime} 10.25^{\prime \prime} \mathrm{E}$ \\
\hline D5 & Old goose feces & Lapersveld Park, Hilversum & $52^{\circ} 12^{\prime} 54.74^{\prime \prime} \mathrm{N}, 5^{\circ} 11^{\prime} 10.25^{\prime \prime} \mathrm{E}$ \\
\hline
\end{tabular}

placing $10 \mathrm{~mL}$ of a $5 \%(v / v)$ solution of the aromatic substrate in dibutyl-phthalate. A solution of $140 \mathrm{gL}^{-1}$ of $\mathrm{NaCl}$ was also added at the bottom of the desiccators to maintain an internal water activity value of 0.9 , and the whole set was incubated at $30^{\circ} \mathrm{C}$ for at least 3 months. After this time, the perlite granules in each flask were washed with 50-60 mL sterile water. One milliliter of 1-, 10-, or 100 -fold dilutions from each soil suspension were plated in duplicate on $2 \%$ malt extract agar containing penicillin and streptomycin and incubated at $30^{\circ} \mathrm{C}$. Colony growth was observed daily, and black yeast-like colonies were transferred to fresh potato dextrose agar plates for purification and provisional identification upon morphological characters.

\section{Molecular Identification}

A sterile blade was used to scrape off the mycelium from the surface of agar plate cultures of previously isolated fungi. DNA was extracted using an Ultra Clean Microbial DNA Isolation Kit (Mobio, Carlsbad, CA 92010, USA) according to the manufacturer's instructions. DNA extracts were stored at $-20^{\circ} \mathrm{C}$ prior to use. The internal transcribed spacer (ITS) regions and the small subunit (ITS15.8S-ITS2) of the rRNA genes were amplified by using the primer set ITS1 (5'-TCC GTA GGT GAA CCT GCG G-3') and ITS4 (5'-TCC TCC GCT TAT TGA TAT GC-3'). PCR reactions were performed on a Gene Amp PCR System 9700 (Applied Biosystems, Foster City, CA, USA) in $50 \mu \mathrm{L}$ volumes containing $25 \mathrm{ng}$ of template DNA, $5 \mu \mathrm{L}$ reaction buffer $\left(0.1 \mathrm{M}\right.$ Tris- $\mathrm{HCl}, \mathrm{pH} 8.0,0.5 \mathrm{M} \mathrm{KCl}, 15 \mathrm{mM} \mathrm{MgCl}_{2}$, $0.1 \%$ gelatine, $1 \%$ Triton $\mathrm{X}-100), 0.2 \mathrm{mM}$ of each dNTP and 2.0 U Taq DNA polymerase (ITK Diagnostics, Leiden, The Netherlands). Amplification was performed with cycles of $2 \mathrm{~min}$ at $94^{\circ} \mathrm{C}$ for primary denaturation, followed by 35 cycles at $94^{\circ} \mathrm{C}(45 \mathrm{~s}), 52^{\circ} \mathrm{C}(30 \mathrm{~s})$ and $72^{\circ} \mathrm{C}(120 \mathrm{~s})$, with a final 7 -min extension step at $72^{\circ} \mathrm{C}$. Amplicons were purified using GFX PCR DNA and gel band purification kit (GE Healthcare, Ltd., Buckinghamshire, UK). Sequence PCR was performed as follows: $95^{\circ} \mathrm{C}$ for $1 \mathrm{~min}$, followed by 30 cycles consisting of $95^{\circ} \mathrm{C}$ for $10 \mathrm{~s}, 50^{\circ} \mathrm{C}$ for $5 \mathrm{~s}$, and $60^{\circ} \mathrm{C}$ for $2 \mathrm{~min}$. Reactions were purified with Sephadex G-50 fine (GE Healthcare Bio-Sciences AB, Uppsala, Sweden), and sequencing was done on an $\mathrm{ABI} 3730 \mathrm{XL}$ automatic sequencer (Applied Biosystems). Sequence data obtained in this study were adjusted using the SeqMan of Lasergene software (DNAStar Inc., Madison, Wisconsin, USA). For the phylogenetic assignment, the obtained DNA sequences were compared against reference sequences by using the BLASTN algorithm on local CBS-KNAW and public GenBank databases (NCBI, USA). Phylogenetic analyses were conducted using MEGA version 4 (Center for Evolutionary Functional Genomics, The Biodesign Institute, USA).

\section{Results}

A total of 71 fungal strains were isolated upon enrichment of environmental samples on atmospheres of different volatile aromatic hydrocarbons (Table 2). Of those, a single mold (Aspergillus fumigatus) other than black yeasts was isolated from berries of Sorbus aucuparia (sample C1). The highest isolation rates were achieved with samples taken 
Table 2 Number of fungal isolates obtained from solid state-like enrichment cultures incubated at $30^{\circ} \mathrm{C}$ and a water activity of 0.9 , under an atmosphere rich in specific volatile aromatic hydrocarbons

\begin{tabular}{lrrrrr}
\hline $\begin{array}{l}\text { Sample } \\
\text { code }\end{array}$ & Benzene & Toluene & Xylene & Naphthalene & $\begin{array}{l}\text { Total } \\
\text { strains }\end{array}$ \\
\hline A1 & 0 & 4 & 11 & 0 & 15 \\
A2 & 0 & 3 & 0 & 0 & 3 \\
A3 & 10 & 8 & 6 & 0 & 24 \\
A4 & 0 & 11 & 0 & 0 & 11 \\
C1 & 0 & $5^{\text {a }}$ & 0 & 0 & 5 \\
C2 & 0 & 7 & 0 & 0 & 7 \\
D2 & 0 & 6 & 0 & 0 & 6 \\
Total & 10 & 44 & 17 & 0 & 71 \\
strains & & & & & \\
\hline
\end{tabular}

${ }^{a}$ One isolated strain within this treatment was identified as Aspergillus fumigatus; this was the only non-black yeast strain from the whole obtained strain collection

from creosoted wooden railway ties, particularly from those arising from the tie section located outside the rails and using toluene as the incubation substrate (39 isolates, samples A1 and A3). These samples were the only ones that yielded isolates when xylene or benzene was applied as enrichment substrates (17 and 10 strains, respectively), but not a single fungus was isolated when naphthalene was supplied as the sole carbon source. Though in lower numbers, black yeasts were also isolated from the tie section located between the rails (14 strains, samples A2 and A4). Besides creosote, these samples were likely to contain fecal and mineral oil contamination as well. No fungal isolates were retrieved from concrete railway ties (sample A5).

From the natural sampled environments, black yeasts were isolated in two out of four berries from $S$. aucuparia (12 isolates, samples $\mathrm{C} 1$ and $\mathrm{C} 2$ ), but no fungi were obtained from berry samples of Viburnum opulus and Crataegus monogyna (samples C5 and C6, respectively). Soil mixed with bird feces (guano) also yielded melanized fungi in one out of five tested samples (six isolates, sample D2). No black yeasts were isolated when suspensions of the samples described above (Table 1) were directly plated onto SGA plates, without the enrichment step on volatile aromatic hydrocarbons, while several common and heavily sporulating fungal species were encountered.

Phylogenetic analysis of aligned ITS1-5.8S-ITS2 rRNA sequences from the obtained strain collection showed that the isolates were affiliated to five major groups (Fig. 1). Sequences from reference strains deposited at the CBS collection (Utrecht, The Netherlands) that were related to the isolates in terms of their sequence homology and/or ecophysiology were also included in the analysis. Those encompassed the type strains of E. xenobiotica, E. bergeri,
Exophiala spinifera, E. oligosperma, E. heteromorpha, E. dermatitidis, E. lecanii-corni, and Phialophora sessilis, as well as from those of the Cladophialophora species that have been so far related to the metabolism of aromatic hydrocarbons: Cladophialophora immunda, C. saturnica, and Cladophialophora psammophila sp. nov., the latter species being in the process of description (Badali et al., submitted). Strains of E. xenobiotica, E. bergeri, and $E$. dermatitidis that have previously been isolated from creosoted railway ties were also used.

Sequence comparisons against those from reference strains revealed that most of the isolates were similar to Exophiala xenobiotica (32 strains). The majority was highly homologous $(\geq 99 \%)$ to the ex-type strain, and some were slightly deviating ( $97 \%$ homology). A second group of isolates (nine strains) was identified as belonging to E. bergeri on the basis of a $99 \%$ sequence homology to the ex-type strain. The cluster encompassing E. bergeri also included a major group (24 strains), the sequence of which deviated significantly from the ex-type strain (94\% sequence homology), so that its affiliation to E. bergeri might be put into question. BLAST searches on this latter group into the GenBank genomic database revealed a close match (98\% homology) with an unidentified Exophiala strain isolated from a rock surface. A minor E. bergeri sibling group was composed of two strains for which no known sequence match was found. A third group (three strains) did not match any known reference type strain, but GenBank searches revealed a high sequence homology $(98 \%)$ to the sequence of an uncultivated fungus from a municipal composting plant.

Except for a single isolate (dH18150) obtained from a S. aucuparia berry (sample $\mathrm{C} 1$ ), the E. xenobiotica-related strains were isolated exclusively from creosoted oak tie sections located outside the rails (samples A1 and A3). Within this group, three strains were obtained under benzene enrichment, while the remaining 29 strains were isolated with toluene or xylene as enrichment substrates. Besides E. xenobiotica, sample A3 also yielded five isolates upon benzene enrichment, which were identified as E. bergeri. The related between-the-rails section from that same tie (sample A4) and the guano-rich soil (sample D2) yielded 1 and 3 strains of E. bergeri, respectively, using toluene as the enrichment substrate.

Figure 1 Neighbor joining phylogenetic tree (Kimura 2-parameter model) on aligned ITS1-5.8S-ITS2 rRNA gene sequences from the fungi isolated in this study, in relation to the isolation sample and enrichment substrate. Sequences from relevant reference type strains (bold characters) and from other isolates obtained previously from creosoted wood and related environments (underlined characters) were also added [26, 27]. For phylogenetically unassigned groups, sequences from close GenBank matches were also included in the analysis (GenBank sequence codes are given between square brackets) 
Taxon

Exophiala xenobiotica CBS 118157

Exophiala xenobiotica dH18121 Exophiala xenobiotica dH18122 Exophiala xenobiotica $\mathrm{dH} 18123$ Exophiala xenobiotica $\mathrm{dH} 18124$ Exophiala xenobiotica $\mathrm{dH} 18137$ Exophiala xenobiotica dH Exophiala xenobiotica dH18139 Exophiala xenobiotica dH18140 Exophiala xenobiotica $\mathrm{dH} 1814$ Exophiala xenobiotica $\mathrm{dH} 18142$ Exophiala xenobiotica $\mathrm{dH} 18143$ Exophiala xenobiotica $\mathrm{dH} 18181$ Exophiala xenobiotica $\mathrm{dH} 18182$ Exophla xenobictica d 18182 Exophiala xenobiolica dH1818 Exophiala xenobiotica dH18158 Exophiala xenobiotica $\mathrm{dH} 18159$ Exophiala xenobiotica $\mathrm{dH} 18160$ Exophiala xenobiotica $\mathrm{dH} 18161$ Exophiala xenobiotica dH18163 Exophiala xenobiotica $\mathrm{dH} 18164$ Exophiala xenobiotica dH18145 Exophiala xenobiotica dH18146 Exophiala xenobiotica dH18147 Exophiala xenobiotica dH18185 Exophiala xenobiotica $\mathrm{dH} 18195$ Exophiala xenobiotica dH18196 Exophiala xenobiotica dH18197 Exophiala xenobiotica dH18150 Exophiala xenobiotica CBS 12282 Exophiala xenobiotica CBS 122828 Exophiala xenobiotica CBS 122829 Exophiala xenobiotica dH18162 Exophiala xenobiotica $\mathrm{dH} 18157$

$-[$ Exophiala xenobiotica CBS 122846

Exophiala oligosperma CBS 725.88 Exophiala spinifera CBS 899.68

Exophiala bergeri CBS 353.52

Exophiala bergeri $\mathrm{dH} 18178$ Exophiala bergeri $\mathrm{dH} 18179$ Exophiala bergeri dH18180 Exophiala bergeri $\mathrm{dH} 18188$ Exophiala bergeri $\mathrm{dH} 18189$ Exophiala bergeri dH18192 Exophiala bergeri $\mathrm{dH} 18193$

Exophiala sp. dH18191

Exophiala sp. dH18190

Exophiala bergeri $\mathrm{dH} 18194$

Exophiala bergeri dH18166 Exophiala bergeri CBS 122841 Exophiala bergeri CBS 122842 Exophiala bergeri CBS 122843 Exophiala bergeri CBS 122844

Exophiala sp. dH18125 Exophiala sp. dH18126 Exophiala sp. dH1812 Exophiala sp. dH18144 Exophiala sp. dH1812 Exophiala sp. dH18129 Exophiala sp. dH18130 Exophiala sp. dH18131 Exophiala sp. dH18132 Exophiala sp dH18165 Exophiala sp. dH18167 Exophiala sp. dH18168 Exophiala sp. dH18168 Exophiala sp. dH18169 Exophiala sp. dH18170 Exophiala sp. dH18149 Exophiala sp. dH18155 Exophiala sp. dH18156 Exophiala sp. dH18133 Exophiala sp. dH18135 Exophiala sp. $\mathrm{dH} 18136$ Exophiala sp. dH18171 Exophiala sp. dH18172 Exophiala sp. dH18172 Exophiala sp. dH18173 Exophiala sp. dH1817

Exophiala sp. TRN14 [AY843049]

Exophiala sp. dH18175

Exophiala sp. dH18176

Exophiala sp. dH18177

Uncultured fungus [FM173097]

Exophiala heteromorpha CBS 232.33

Exophiala dermatitidis CBS 207.35

Exophiala dermatitidis CBS 122830

Exophiala dermatitidis CBS 116726
Isolation source (sample/location)

Substrate

Creosoted tie, outside rails (A1)

Creosoted tie, outside rails (A1)

Creosoted tie, outside rails (A1)

Creosoted tie, outside rails (A1)

Creosoted tie, outside rails (A1)

Creosoted tie, outside rails (A1)

Creosoted tie, outside rails (A1)

Creosoted tie, outside rails (A1)

Creosoted tie, outside rails (A1)

Creosoted tie, outside rails (A1)

Creosoted tie, outside rails (A1)

Creosoted tie, outside rails (A1)

Creosoted tie, outside rails (A1)

Creosoted tie, outside rails (A1)

Creosoted tie, outside rails (A1)

Creosoted tie, outside rails (A3)

Creosoted tie, outside rails (A3)

Creosoted tie, outside rails (A3)

Creosoted tie, outside rails $(A 3)$

Creosoted tie, outside rails (A3)

Creosoted tie, outside rails (A3)

Creosoted tie, outside rails (A3)

Creosoted tie, outside rails (A3)

Creosoted tie outside rails (A3)

Creosoted tie, outside rails (A3)

Creosoted tie, outside rails (A3)

Creosoted tie, outside rails (A3)

Creosoted tie, outside rails (A3)

Creosoted tie, outside ralls (A3)

Creosoted tie (Rio Claro, Brazil)

Creosoted tie (Rio Claro, Brazil)

Creosoted tie, outside rails (A3)

Creosoted tie, outside rails (A3)

Creosoted tie, (Rio Claro, Brazil)

Creosoted tie, outside rails (A3)

Guano rich soil (D2)

Guano rich soil (D2)

Guano rich soil (D2)

Creosoted tie, outside rails (A3)

Creosoted tie, outside rails (A3)

Creosoted tie, outside rails (A3)

Creosoted tie, outside rails (A3)

Creosoted tie, outside rails (A3)

Creosoted tie, outside rails (A3)

Creosoted tie, outside rails (A3)

Creosoted tie, between rails (A4)

Creosoted tie (Rio Claro, Brazil)

Creosoted tie (Rio Claro, Brazil)

Creosoted tie (Rio Claro, Brazil)

Creosoted tie (Rio Claro, Brazil)

Oak railway tie, between rails (A2)

Oak railway tie, between rails (A2)

Oak railway tie, between rails (A2)

Creosoted tie, outside rails $(A 3)$

Oak railway tie, between rails (A4)

Oak railway tie, between rails (A4)

Oak railway tie, between rails (A4)

Oak railway tie, between rails (A4)

Oak railway tie, between rails (A4)

Oak railway tie, between rails (A4)

Oak railway tie, between rails (A4)

Oak railway tie, between rails (A4)

Oak railway tie, between rails (A4)

Oak railway tie, between rails (A4)

Berry, Sorbus aucuparia (C1)

Berry, Sorbus aucuparia (C1)

Berry, Sorbus aucuparia (C1)

Berry, Sorbus aucuparia (C2)

Berry, Sorbus aucuparia (C2)

Berry, Sorbus aucuparia (C2)

Berry, Sorbus aucuparia (C2)

Berry, Sorbus aucuparia (C2)

Berry, Sorbus aucuparia (C2)

Berry, Sorbus aucuparia (C2)

Rock surface (Spain)

Guano rich soil (D2)

Guano rich soil (D2)

Guano rich soil (D2)

municipal waste compost (Finland)

Toluen

Toluene

Toluene

Toluene

Xylene

Xylene

Xylene

Xylene

Xylene

Xylene

Xylene

Xylene

Xylene

xylene

Xylene

Xylene

Toluene

Toluene

Toluene

Toluene

Toluene

Toluene

Xylene

Xylene

Xylene

Xylene

Benzene

Benzene

Benzene

Toluene

Toluene

Toluene

Xylene

Toluene

Toluene

Toluene

Benzene

Benzene

Benzene

Benzene

Benzene

Benzene

Benzene

Toluene

Toluene

Toluene

Toluene

Xylene

Toluene

Toluene

Toluene

Toluene

Toluene

Toluene

Toluene

Toluene

Toluene

Toluene

Toluene

Toluene

Toluene

Toluene

Toluene

Toluene

Toluene

Toluene

Toluene

Toluene

Toluene

Toluen

Creosoted tie (Rio Claro, Brazil)

Stone railway contaminated with oil (Thailand) Phialophora sessilis CBS 238.93

Cladophialophora psammophila CBS 110553

Cladophialophora saturnica CBS 114326 


\section{Discussion}

The occurrence of black yeasts in the human-dominated environment has previously been underestimated due to the application of routine microbial isolation methods. Under common laboratory culture conditions, black yeasts are seldom encountered due to their slow growth and limited competitive abilities. Numerous protocols for the selective isolation of black yeasts have been developed during the last decades (an overview is presented in Table 3), which have yielded new data on the presence of these fungi in a wide range of artificial environments, sometimes with no obvious counterpart in nature. Several methods are based on osmotolerant and oligotrophic abilities of target fungi. With these regimens, the isolated black yeasts are mainly osmotolerant members of the saprophytic order Dothideales, although the rockinhabiting fungi appear to be an area of overlap between the Dothideales and the Chaetothyriales. Applying enrichment methods based on the inoculation of rodents, exposure to aromatic hydrocarbons, assimilation of rare sugars, and/or incubation at high temperature, most isolated black yeast-like fungi are members of the Chaetothyriales. It should be noted though that neither of these enrichment conditions might represent the natural niche for these fungi, and they are therefore classified with difficulty in any of the known ecological categories.

The present study demonstrates that enrichment on inert solid media incubated under a controlled atmosphere rich on volatile aromatic hydrocarbons compounds displays an extraordinary selectiveness toward chaetothyrialian fungi from the Herpotrichiellaceae family. For example, under hydrocarbon atmospheres, the berry samples were free from Aureobasidium pullulans, which is a member of the Dothideales, otherwise an extremely common component of honeydew mycobiota and slightly osmotic surfaces of fruits and berries. This species was encountered abundantly along with many contaminants on SGA control plates without alkylbenzene enrichment. The presence of heavily sporulating airborne fungi, frequently found in soil and litter, was strongly reduced by alkylbenzenes and limited to a single strain of $A$. fumigatus. Interestingly, the dothidiaceous species Amorphoteca resinae, known as "creosote fungus" for its common isolation from creosoted wood [17], was found neither in this study nor in previous fungal isolation surveys from creosoted wood [26, 27].

Consistent and relatively abundant isolation of herpotrichiellaceous black yeasts from unpolluted environmental samples, such as wild berries, only after addition of volatile aromatic hydrocarbons strongly suggests that these substances play an essential role in the ecology and competitive ability of those fungi. In particular, the utilization of aromatic compounds as carbon and energy source might explain the key factor determining their success in anthropized environments. With advanced analytical techniques, it has been shown that volatile aromatic hydrocarbons that traditionally were associated with environmental pollution are in fact ubiquitously present in nature, though at very low concentrations. Toluene, for example, is produced biologically in different natural environments including maturing berries [14]. On the other hand, as extremophilic and slow-growing microorganisms, incubation on a support that is relatively

Table 3 Overview of selective methods used for environmental isolation of black yeasts and related melanized fungi, with approximate results

\begin{tabular}{|c|c|c|c|c|}
\hline Method & Prevalent genus & Order & Ecology & Reference \\
\hline Animal bait & Exophiala, Fonsecaea, Cladophialophora & Chaetothyriales & Opportunists & {$[2,8]$} \\
\hline Erythritol & Exophiala & Chaetothyriales & Opportunists & [4] \\
\hline Mineral oil & Exophiala, Fonsecaea & Chaetothyriales & Opportunists & [27] \\
\hline Raulin $40^{\circ} \mathrm{C}$ & Exophiala & Chaetothyriales & Opportunists & [26] \\
\hline Needle & Coniosporium & Chaetothyriales & Rock fungi & {$[30]$} \\
\hline Alkylbenzene vapors & Cladophialophora, Exophiala & Chaetothyriales & Xenobiotics & [20] \\
\hline \multirow[t]{2}{*}{ Acidic } & Exophiala & Chaetothyriales & Acidophiles & [23] \\
\hline & Hortaea & Dothideales & & [12] \\
\hline \multirow[t]{2}{*}{ Crush } & Coniosporium & Chaetothyriales & Rock fungi & [22] \\
\hline & Hormonema & Dothideales & & \\
\hline \multirow[t]{3}{*}{ Low strength } & Exophiala & Chaetothyriales & Oligotrophs & {$[10]$} \\
\hline & Sarcinomyces & Dothideales & Rock fungi & {$[30]$} \\
\hline & Cadophora & Leotiales & Oligotrophs & {$[1]$} \\
\hline High salt & Aureobasidium, Hortaea & Dothideales & Halophiles & {$[31,32]$} \\
\hline Suspend & Cryomyces, Friedmanniomyces & Dothideales & Psychrophiles & {$[25]$} \\
\hline Ethanol & Baudoinia & Dothideales & Ethanophiles & [9] \\
\hline
\end{tabular}


dry and poor in nutrients is also a determinant factor for the enrichment of black yeasts, when compared to traditional liquid enrichment cultures [20].

Regarding both the presence of aromatic compounds and exposure to fluctuating and/or extreme environmental conditions, wood treated with creosote can be regarded as a paradigmatic environmental niche for black yeasts. Creosote is a distillate derived entirely from tar, which is rich in a wide variety of polycyclic aromatic hydrocarbons, phenols, and cresols, and has widely been used as wood preservative against microbial decay. Due to its carcinogenic character, the use of creosote has been banned in the European Union. Yet, creosoted wood utilities are still widely present in the open environment, such as telephone poles, railway cross ties, switch ties, and bridge timbers. Also, creosote is an important soil contaminant in former wood creosoting plants.

In a previous study, E. dermatitidis was isolated from wild berries and massively from creosoted railway ties in Thailand when using the pre-incubation in Raulin's solution at low $\mathrm{pH}$ and incubated at $40^{\circ} \mathrm{C}$, this protocol being quite selective for $E$. dermatitidis [26]. It was hypothesized that the life cycle of this species involved the occurrence on wild berries, ingestion and passage through the human intestinal tract, and feces deposition on railway ties. Subsequent enrichment on creosoted wood might then be related not only to the oligotrophy, thermotolerance (particularly under tropical conditions), acidotolerance, and moderate osmotolerance of $E$. dermatitidis but also to the presence of aromatic compounds. The temperate wild berry sampling locations that were the subject of our study (Table 1) had previously been analyzed for the occurrence of black yeasts $[18,26]$. Collected berries were homogenized, diluted, and used for spread plates or were subjected to the Raulin's pre-incubation protocol. In these earlier studies involving several hundreds of samples, only a single strain of $E$. dermatitidis was isolated from a berry of $S$. aucuparia. The lack of this fungus in temperate climate conditions suggests that E. dermatitidis has an origin in the tropics. This hypothesis is further supported by the isolation of $E$. dermatitidis from creosoted railway ties in Brazil [27], using the mineral oil-flotation protocol $[15,24]$.

From the present enrichment program on volatile alkylbenzenes, it appears that Exophiala species, though other than the thermophilic E. dermatitidis, are regularly present on substrates that are characteristic from the latter species (berries, bird feces, and creosoted railway ties). The most frequently isolated species, E. xenobiotica, has been described only recently [6]. It is known to be associated with mild cutaneous infections in humans [33] and is also commonly found in habitats rich in xenobiotics such as hydrocarbon-polluted soil and gas biofilters for the biodeg- radation of BTEX compounds $[6,24,26]$. E. bergeri was frequently isolated in the presence of toluene and benzene. Until recently, it was regarded to be an extremely rare opportunist, although a recent study showed that it was underdiagnosed due to a general lack of application of sequencing for identification [33]. Using the selective oil-flotation method, E. bergeri was isolated from samples of wood treated or non-treated with creosote preservatives [27]. A distinct cluster was identified within the E. bergeri group, which might belong to a yet-undescribed species. Strains from this group were predominantly isolated from the section between the rails of sampled wooden ties, which were partly contaminated by machine oil and human feces. The remaining strains of E. xenobiotica and E. bergeri senso stricto were obtained from the section outside the rails, where this contaminating effect was less marked. Three identical strains were isolated from guano-rich soil covered with Hedera by enrichment under a toluene atmosphere. No close sequence homology against reference strains was found for these fungi, indicating that a yet-undescribed species is concerned. The phylogenetic affiliation of the undescribed strains will be reported in detail in a subsequent study.

The extremophilic nature of black yeast, in combination with their capacity to metabolize aromatic pollutants, makes them ideal candidates for specific bioremediation purposes. Prospects on the biotechnological application of these fungi until recently have been hampered by potential biohazard [21], but, as phylogenetic data on these organisms accumulates, it seems that severe pathogens and hydrocarbon-associated species are consistently wellseparated siblings (de Hoog, unpublished). Indeed, enrichment on volatile aromatic hydrocarbons in gas biofilters and similar systems thus far has never yielded pathogenic species of the higher fungal biohazard risk categories, such as Cladophialophora bantiana or E. dermatitidis. This suggests that a certain degree of speciation between pathogenic and aromatic hydrocarbon metabolizing species has occurred in evolutionary terms. Yet, more studies are needed to emphasize the importance of selective methods to isolate black yeasts and acquire more understanding of their ecological niches. The application of the enrichment method used in the present paper contributes to the isolation of fungi that have a potential for bioremediation of sites polluted with monoaromatic hydrocarbons.

Acknowledgments This project was partly supported by Program for New Century Excellent Talents in Fujian Province University (NCETFJ-0706), the Grant from Education Department of Fujian Province (NO. JA06013), the China Exchange Program of the Netherlands Academy of Sciences, and by the Agència de Residus de Catalunya (Generalitat de Catalunya). We also acknowledge Marc Viñas and Miriam Guivernau for the critical reading of the manuscript. 
Open Access This article is distributed under the terms of the Creative Commons Attribution Noncommercial License which permits any noncommercial use, distribution, and reproduction in any medium, provided the original author(s) and source are credited.

\section{References}

1. Badali H, Gueidan C, Najafzadeh MJ, Bonifaz A, van den Ende AHGG, de Hoog GS (2008) Biodiversity of the genus Cladophialophora. Stud Mycol 61:175-191

2. Conti-Díaz IA, Mackinnon JE, Civila E (1977) Isolation and identification of black yeasts from the external environment in Uruguay. Pan Amer Health Org Sci Publ 356:109-114

3. Cox HHJ, Houtman JHM, Doddema HJ, Harder W (1993) Growth of the black yeast Exophiala jeanselmei on styrene and styrene-related compounds. Appl Microbiol Biotechnol 39:372-376

4. de Hoog GS, Haase G (1993) Nutritional physiology and selective isolation of Exophiala dermatitidis. Antonie Van Leeuwenhoek 64:17-26

5. de Hoog GS, Hermanides-Nijhof EJ (1977) The black yeasts and allied hyphomycetes. Stud Micol 15:222

6. de Hoog GS, Zeng JS, Harrak MJ, Sutton DA (2006) Exophiala xenobiotica sp. nov. an opportunistic black yeast inhabiting environments rich in hydrocarbons. Antonie Van Leeuwenhoek 90:257-268

7. de Hoog GS, Vicente V, Caligiorne RB, Kantarcioglu S, Tintelnot K, Gerrits van den Ende AH, Haase G (2003) Species diversity and polymorphism in the Exophiala spinifera clade containing opportunistic black yeast-like fungi. J Clin Microbiol 41:4767-4778

8. Dixon DM, Walsh TJ, Merz WG, McGinnis MR (1989) Infections due to Xylohypha bantiana (Cladosporium trichoides). Rev Infect Dis 11:515-525

9. Ewaze JO, Summerbell RC, Scott JA (2008) Semiselective isolation of the ethanol-imbibing sooty mould Baudoinia of distillery aging warehouses. Can J Microbiol 54:331-333

10. Göttlich E, van der Lubbe W, Lange B, Fiedler S, Melchert I, Reifenrath M, Flemming H-C, de Hoog GS (2002) Fungal flora in groundwater-derived public drinking water. Intern J Hyg Environm Health 205:269-279

11. Haase G, Sonntag L, Melzer-Krick B, de Hoog GS (1999) Phylogenetic inference by SSU-gene analysis of members of the Herpotrichiellaceae with special reference to human pathogenic species. Stud Mycol 43:80-97

12. Hölker U, Bend J, Pracht R, Müller T, Tetsch L, Höfer M, de Hoog SG (2003) Hortaea acidophila, a new acid-tolerant black yeast from lignite. Antonie Van Leeuwenhoek 86:287-294

13. Horre R, de Hoog GS (1999) Primary cerebral infections by melanized fungi: a review. Stud Mycol 43:176-193

14. Horvat RJ, Senter SD (1984) Identification of the volatile constituents from scuppernong berries (Vitis rotundifolia). J Food Sci 49:64-66

15. Iwatsu T, Miyaji M, Okamoto S (1981) Isolation of Phialophora verrucosa and Fonsecaea pedrosoi from nature in Japan. Mycopathologia 75:149-158
16. Kennes C, Veiga MC (2004) Fungal biocatalysts in the biofiltration of VOC-polluted air. J Biotechnol 113:305-319

17. Marsden DH (1954) Studies of the creosote fungus, Hormodendrum resinae. Mycologia 46:161-183

18. Matos T, de Hoog GS, de Boer AG, de Crom I, Haase G (2002) High prevalence of the neurotrope Exophiala dermatitidis and related oligotrophic black yeasts in sauna facilities. Mycoses 45:373-377

19. Middelhoven WJ, de Jong IM, de Winter M (1991) Arxula adeninivorans, a yeast assimilating many nitrogenous and aromatic compounds. Antonie Van Leeuwenhoek 59:129-137

20. Prenafeta-Boldú FX, Kuhn A, Luykx D, Anke H, van Groenestijn JW, de Bont JAM (2001) Isolation and characterisation of fungi growing on volatile aromatic hydrocarbons as their sole carbon and energy source. Mycol Res 105:477-484

21. Prenafeta-Boldú FX, Summerbell R, Sybren de Hoog G (2006) Fungi growing on aromatic hydrocarbons: biotechnology's unexpected encounter with biohazard? FEMS Microbiol Rev 30:109130

22. Ruibal C (2004) Isolation and characterization of melanized, slow-growing fungi from semiarid rock surfaces of central Spain and Mallorca. Thesis, Madrid, Spain, p 167

23. Rustler S, Stolz A (2007) Isolation and characterization of a nitrile hydrolysing acidotolerant black yeast-Exophiala oligosperma R1. Appl Microbiol Biotechnol 75:899

24. Satow MM, Attili-Angelis D, de Hoog GS, Angelis DF, Vicente VA (2008) Selective factors involved in oil flotation isolation of black yeasts from the environment. Stud Mycol 61:157-163

25. Selbmann L, de Hoog GS, Mazzaglia A, Friedmann EI, Onofri S (2005) Fungi at the edge of life: cryptendolithic black fungi from Antarctic desert. Stud Mycol 51:1-32

26. Sudhadham M, Haase G, Prakitsin S, de Hoog GS (2008) The neurotropic black yeast Exophiala dermatitidis indicate a possible origin of in the tropical rain forest. Stud Mycol 61:145-155

27. Vicente VA, Attili-Angelis D, Pie MR, Queiroz-Telles F, Cruz LM, Najafzadeh MJ, de Hoog GS, Pizzirani-Kleiner A (2008) Environmental isolation provides recognition of relative virulence of black yeast-like fungi. Stud Mycol 61:137-144

28. Wang CJK, Zabel RA (1990) Identification manual for fungi from utility poles in the Eastern United States. Allen, Lawrence

29. Weber FJ, Hage KC, de Bont JAM (1995) Growth of the fungus Cladosporium sphaerospermum with toluene as the sole carbon and energy source. Appl Environ Microbiol 61:3562-3566

30. Wollenzien U, de Hoog GS, Krumbein W, Uijthof JMJ (1997) Sarcinomyces petricola, a new microcolonial fungus from marble in the Mediterranean basin. Antonie Van Leeuwenhoek 71:281288

31. Zalar P, de Hoog GS, Gunde-Cimerman N (1999) Ecology of halotolerant dothideaceous black yeasts. Stud Mycol 43:38-48

32. Zalar PMG, Gunde-Cimerman N, Sudhadham M, de Hoog GS (2008) Biodiversity of Aureobasidium in Arctic glaciers. Stud Mycol 61:21-38

33. Zeng JS, Sutton DA, Fothergill AW, Rinaldi MG, Harrak MJ, de Hoog GS (2007) Spectrum of clinically relevant Exophiala species in the U.S.A. J Clin Microbiol 45:3713-3720 